\title{
Analyses on the Present Situation of Chinese Language Teaching and Corresponding Measures in Colleges
}

\author{
Jie $\mathrm{Lu}^{1, \mathrm{a}}$ \\ ${ }^{1}$ Beihua University Teacher's College, Jilin, Jilin, China \\ a13961671@qq.com
}

Keywords: Chinese; language teaching; Theory; Practice

\begin{abstract}
Presently, Chinese language teaching is a main foundation course of liberal arts education, playing an indispensable role in cultivating students' comprehensive quality and inheriting traditional culture. In order to solve the problems existing in Chinese language teaching in colleges in our country, colleges teachers should strive to improve the students' ability and enhance the effect of ideology and morality cultivation, integrating teaching of theory and practice. Flexible and varied teaching methods should be adopted such as classroom teaching and extracurricular activities, outstanding practicality and application of Chinese language teaching. Introduction of independent learning mode stimulates students learning interest and motivation. Standard professional Chinese teaching curriculum and training objectives fully improve the quality of the language teaching and the overall level of teachers.
\end{abstract}

\section{Introduction}

The National Department of Education has clearly pointed out that colleges and universities must set Chinese language courses for all students involved. Chinese language curriculum standards also require that language teaching should motivate students' interest, focus on cultivating students' independent learning awareness and habits, create friendly independent learning circumstances for students, respect students' individual differences, and encourage students to choose their own learning methods[1]. Chinese language course plays an irreplaceable role in training students' listening, speaking, reading and writing ability and in the liberal education which contains culture of literature and art, philosophy of history, residents' civility, ethical and moral principles. From this perspective, Chinese language teaching is crucial to the thought and culture construction of contemporary China.

\section{The Problems of Chinese Language Teaching in Colleges}

\section{Without enough attention}

Some colleges do not pay enough attention to Chinese language teaching, resulting in language courses have been canceled in some universities of science and technology as well as science departments[2]. Many Chinese language teachers are forced to meet the teaching period requirements of colleges by teaching specialized courses, or by setting optional courses such as mandarin, speech and writing, literature appreciation, making the marginalization of Chinese language teachers more serious.

\section{Out-of-date teaching contents}

Confronted with current diversified cultural trends and employment pressure of two-way choice, Chinese teaching contents of many colleges seem to fall behind the times. Necessary abilities of oral expression, practical writing, analysis and summary, interpersonal communication for students to enter the service and blend into society have failed to meet the expectations of society and school requirements. And the resulting effects of students' low learning interest, the single assessment method, and the realistic requirement of society gradually form the vicious circulation.

\section{Weak practice}

Chinese language teaching is a comprehensive curriculum that integrates outstanding cultural 
heritage, spirit cultivation into application of practical skills. Among them, the application of practical skills reflects the most realistic and direct effect. However, a lot of colleges still adopt traditional "method of lecture" in language teaching at present. Focusing on imparting knowledge and ignoring practice cannot mobilize students' learning initiative and enthusiasm, and fail to cause the effect of the language learning in training students' comprehensive literacy guided by future employment, which includes analysis and understanding ability, speaking ability, reading appreciation ability, practical writing ability.

\section{Reflection on Chinese Language Teaching in Colleges}

In view of the important part that Chinese language plays in students' growing up, communication and employment, and increasingly weakening and uncoordinating phenomenon in reality, the colleges and the language teachers should think and act, through great efforts, making college Chinese teaching pay equal attention to theory and practice[3]. Guided by students' future employment, students should be provided with all-round, multi-angle understanding ability, well-equipped spoken language, reading appreciation and practical writing skills. Students can master certain skills in listening, speaking, reading and writing, to understand and communicate. The teachers should arouse students' interest in language learning, help them master some Chinese language learning methods, and develop good study habits.

To strengthen students' ability and ideological cultivation, theory should be integrated with practice.

Chinese language teaching in colleges should take into consideration of both students' ability training and ideological cultivation, putting equal emphasis on language qualities of instrument and humanism, which are interdependent, and neither is dispensable [4]. Chinese language teachers should get the awareness that language teaching in middle school emphasizes groundwork, while colleges focus on improving the students' literary cultivation, helping students develop good moral character, mastering abilities of listening, speaking, reading and writing, etc. We broaden students' minds, improve their literary and artistic cultivation through Chinese language teaching for students to benefit from the edification of the noble sentiment and good character. At the same time, Chinese language teaching in colleges should set the goals of Chinese language education, pay attention to its humanity based on the characteristics of the college students. No matter what kind of jobs the students will take after graduation, moral cultivation, literature accomplishment, aesthetic temperament and interest will be of great help to their life and career. Chinese language education in colleges, on the one hand, develops students' love for mother language of Chinese nation, making them get the awareness of language specification, and communicate accurately; on the other hand, learning time-honored traditional culture, cultivates students' good moral character, aesthetic, cultural quality, promoting excellent Chinese culture convert into the students' psychological quality and morality, improving the general quality of students.

\section{Flexible and varied teaching methods such as classroom teaching and extracurricular guide stick out practical needs and application of Chinese language teaching.}

First of all, it must adhere to the principle of combining classroom contents with extracurricular activities, scientifically and reasonably integrating and cutting teaching contents. With emphasis on practical needs and application of theoretical teaching, it bands imparting knowledge and cultivating talents together. Secondly, Chinese language teaching in colleges should reform and perfect teaching forms and methods. According to different teaching contents, teachers should try to adopt various and vivid teaching methods, making students the hosts of the classroom, exerting students' initiative and creativity, motivating the students' study enthusiasm as much as possible. Thirdly, Chinese language teachers in colleges should teach and guide students according to the characteristics of the students major in different disciplines, training requirements, and their aptitude, making them not only master the theoretical knowledge needed for the general people, but also possess professional ability to carry out a specific task by learning Chinese language. In addition, Chinese language teaching in colleges should make full use of modern teaching methods and extracurricular activities liked to see and hear by students, engaging in comprehensive and 
integrated teaching activities, enriching teaching forms, stimulating interest, to increase teaching effect.

\section{To stimulate students' interest and motivation in Chinese language, we can introduce independent learning mode.}

Chinese teaching should arouse students' interest in learning, set friendly independent learning circumstance for students, respect their differences, and encourage students to choose for their own learning methods suitable for themselves. To do this, the first is to create democratic atmosphere in classroom teaching [5]. Chinese teaching should be a two-way activity between teachers and students, which is information transmission process that requires participation from both sides. The language teachers must abandon the traditional teaching ideas and methods, making efforts to create democratic and harmonious teaching atmosphere, trying to invite students participate in teaching process, which reflects the real democracy.

\section{The second is to develop multidirectional understanding in students.}

Knowledge is the product of wisdom, but possessing knowledge is not equal to having wisdom. Knowledge can be passed, but not wisdom. From the perspective of individual cognition, any insight is the product of self-construction in activities. Insight is the unity of knowledge and wisdom. Thus, teachers should pay special attention to respecting students' unique ideas and opinions, not casually denying student's understanding, encouraging students to conduct multi-understanding from different angles, different starting points. The third is to help students set self-learning goals. There are imbalance and differences in learning ability between students. Chinese language teaching should not only develop students' self-learning awareness and habits, but also take individual differences into account. Students themselves should set self-study goals before class, which is precondition for them to learn on their own. Teachers can't replace these goals with general self-study targets given to all students.

To fully improve the quality of Chinese teaching and the overall level of teachers, teaching curriculum and training objectives should be standardized. Taking into consideration that many college students lack humanity cultivation, and application of Chinese language is poor, colleges should make Chinese language as a common course for all the institutes, and besides this, set elective course according to actual needs of majors. As to assessment, teachers can take example by forms of grade examination from English, computer, mandarin. According to different features of arts and science, teachers design different assessment contents and set assessment standards, to check college students' language skills.

In the meantime, teachers should get advanced studies and regular training, in order to improve the overall level of Chinese teachers, making them become integrated talents to win students over with professional training and the breadth of knowledge. Chinese language teachers should be encouraged to become "double-qualified" talents as some specialized teachers do. For example, they take an active part in all kinds of industries such as mandarin testers, tour guides. In doing this, they can broaden their knowledge, enrich teaching contents, and dedicate themselves whole-heartedly to the cause of higher vocational education.

In summary, Chinese language teaching in colleges should strengthen the cultivation of student's ability and idea on the basis of the profound cultural accumulation, making it yield returns of education, navigation, and leading. Only in this way, can Chinese language teaching in colleges play a more important role in improving culture quality.

\section{References}

[1] Dongmei Zhang. Social Scientists Talking about Strengthening Colleges Students Cultural Quality [J]. Journal of Education Research, 2002.

[2] Min Xiao. The Similarities and Differences of Concepts in Chinese Teaching between Secondary School and College [J]. Chinese Language Teaching Research, 2004..

[3] Shu-e Liu. About the Discussion of How to Position "College Chinese" in colleges [J]. Journal 
of Liaoning Institute of Education Administration, 2007 (4).

[4] Hai-ping Zhu. College Chinese: the Required Course of Humanistic Qualities [J]. Journal of Shaoxing Liberal Art \&Science College, 2003 (11).

[5] Guo-qing $\mathrm{Wu}$, Brief Analysis of College Chinese Teaching in the Context of the New Curriculum [J],Journal of Anhui Science and Technology University,2011(1). 